\title{
Notas sôbre os gêneros Polygonanthus e Anisophyllea
}

\author{
JoÃo MURÇA PIRES (*) \\ Instituto de Pesquisas e Experimenta- \\ ção Agropecuárias do Norte. \\ WILLIAM A. RODRIGUES (*) \\ Instituto Nacional de Pesquisas \\ da Amazônia
}

INTRODUÇÃo

Com os comentários apresentados a seguir, temos o propósito de elucidar um problema obscuro que envolve as relações de afinidade de um grupo de plantas constituído por quatro gêneros - Anisophyllea, Polygo nanthus, Combretocarpus e Poga - sendo que o primeiro habita tanto o Velho como o Nôvo Mundo, o segundo é exclusivamente amazônico e os dois últimos são próprios do Velho Mundo. Trata-se de um assunto muito interessante, relacionado com os problemas de evolução, especiação e dispersão das plantas $\mathrm{e}$ serve de argumento favorável às teorias que procuram explicar a antiga ligação dos continentes sul-americano e africano.

\section{COMENTÁRIOS}

\section{Gênero Polygonanthus Ducke}

No que concerne à flora amazônica, o problema acima referido surgiu em 1932, quando Ducke $(1932,1933)$ publicou a descrição do nôvo gênero Polygonanthus, colocando-o dentro da família das Euphorbiaceae, com uma única espécie ( $P$. amazonicus), endêmica das vizinhanças de Maués, no Amazonas.

Ducke, em conversa informal, aliando seu profundo saber com a espirituosidade que Jhe era peculiar, chegou a comentar que realmente Polygonanthus não se enquadrava den- tro das Euphorbiaceae, mas que, casos complicados como êsse, êle usava colocar provi. sòriamente dentro dessa complexa família, onde caberia qualquer coisa.

Em 1939, Croizat, examinando o espécime-tipo fornecido por Ducke e dispondo sòmente de flôres femininas, chegou à conclu. são de que Polygonanthus amazonicus pertencia às Olacaceae, porém não se ajustava a nenhuma das subfamílias existentes, sendo necessária a descrição da nova subfamília Polygonantheae, que colocou entre Dysolacoideae e Olacoideae, na proximidade do gênero Heisteria. Os caracteres principais da nova subfamília seriam: cołumela atingindo o ápice do ovário; ovário ínfero, 4-locular; óvulo com tegumento; fruto geralmente com um só lóculo.

Logo a seguir, no mesmo ano, Baehni e Dansereau (1939) classificaram a interpretação de Croizat como errônea e tentaram demonstrar que $P$. amazonicus pertencia às Saxifragaceae, ficando próximo ao gênero norte-americano Whipplea.

Croizat não tardou em replicar (1939), mantendo sua posição anterior e demonstrando que Polygonanthus não poderia ser colocado entre as Saxifragaceae.

Em 1940, Kuhlmann descreveu uma segunda espécie (Polygonanthus punctulatus) da região do Rio Negro, referindo-a ainda às Euphorbiaceae.

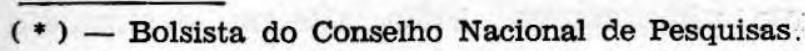


Em 1943, Croizat resolveu descrever a nova família Polygonanthaceae, para abrigar o aberrante gênero Polygonanthus.

Em 1944, Kuhlmann numa nota prévia comunicou sua abalizada opinião final sôbre o assunto : "o gênero Polygonanthus não é de fato uma subfamília das Euphorbiáceas, como supus, nem das Olacáceas onde a princípio o considerou Leon Croizat, nem tão pouco da família Polygonanthaceae Croizat, agora criada, mas simplesmente um gênero da subfamília Anisophylloideae, portanto uma Rhizophoraceae".

Em 1952 Sandwith, descreveu uma nova espécie de Anisophyllea (A. guianensis) coletada por Fanshave na Guiana Inglêsa, sem entretanto descobrir o parentesco dessa planta com as duas espécies de Polygonanthus.

Erdtmann (1966) descreveu o pólen de Polygonanthus amazonicus em Saxifragaceae. Em 1955, em comunicação pessoal, ao receber flôres por nós enviadas da mesma espécie (Pires, 53), informou que "According to the pollen morphological data it seems quite impossible to refer Polygonanthus to the Olacaceae (as Croizat does) or to the Proteaceae. Nor is there any similarity to Rhizophoraceae. On the other hand, pollen morphology does not contradict the reference of Polygonanthus to the Euphorbiaceae or to Saxifragaceae.

It may be added that the pollen grains in Polygonanthus have several characters (size. apertures, several exine details) in common with a family not found in South America, viz. the Pittosporaceae (particularly the genera Pittosporum and Billardiella". (carta de 5 dez. 1955).

\section{Gênero Anisophyllea R. Br. ex Sabine}

O gênero Anisophyllea, criado em 1824, contém cêrca de duas dezenas de espécies descritas que, até 1952, eram consideradas exclusivamente do Velho Mundo tropical, África, Ásia e Arquipélago Malaio.

Sandwith, ao descrever a Anisophyllea guianensis, apresenta um esclarecido comen- tário sôbre a nova espécie descoberta, entretanto não faz menção alguma do seu parentesco com Polygonanthus. Forneceli material da nova espécie a especialistas para a análise química e anatômica. Assim, Chenery (citado por êle) verificou que, como nas outras espécies do gênero, a espécie guian€nse acumula alumínio nas fôlhas $(1,12 \%)$. O estudo anatômico da madeira de raminhos herborizados foi feito por Metcalfe.

Recentemente, várias coleções foram feitas por R. L. Froes, E. Oliveira e W. A. Rodrigues, de uma segunda espécie amazônica de Anisophyllea (A. manauensis) que vai descrita mais adiante.

Nem sempre houve plena concordância entre os diferentes autores sôbre a posição filogenética de Anisophyllea. Segundo Baillon (1877) o gênero é mencionado como membro da tribo Anisophylleae das Rhizophoraceae com referências de que o mesmo já foi tratado dentro das Saxifragaceae. Na "Petite Flore de L'Ouest Africain" de G. Roberty (1954) Anisophyllea laurina é até colocada nas $M e-$ lastomataceae. Ridley (1952) e depois Corner (1952) consideraram Anisophylleaceae como uma família independente, ao se reportar ao gênero em questão.

Como já foi dito, Croizat (1943) não percebeu as relações de parentesco entre Polygonanthus e Anisophyllea ao criar a família Polygonainthaceae, o mesmo acontecendo com Sandwith (1952).

Pelo visto, êste intrincado assunto temnos interessado já há bastante tempo. Agora, com a descoberta da segunda espécie de Anisophyllea, abaixo descrita, resolvemos apresentar, mesmo que em caráter preliminar, a nossa opinião sôbre o intrincado assunto.

\section{Nova espécie de Anisophyllea}

Anisophyllea manausensis. Pires \& Rodr., n. sp. (Fig. 1).

Arbor $10-25 \mathrm{~m}$ alta $18-66 \mathrm{~mm}$ diametro Ramuli terminales tenues, rigidi, vulgo cinereo nigrescentes. Folia alterna, exstipulata 


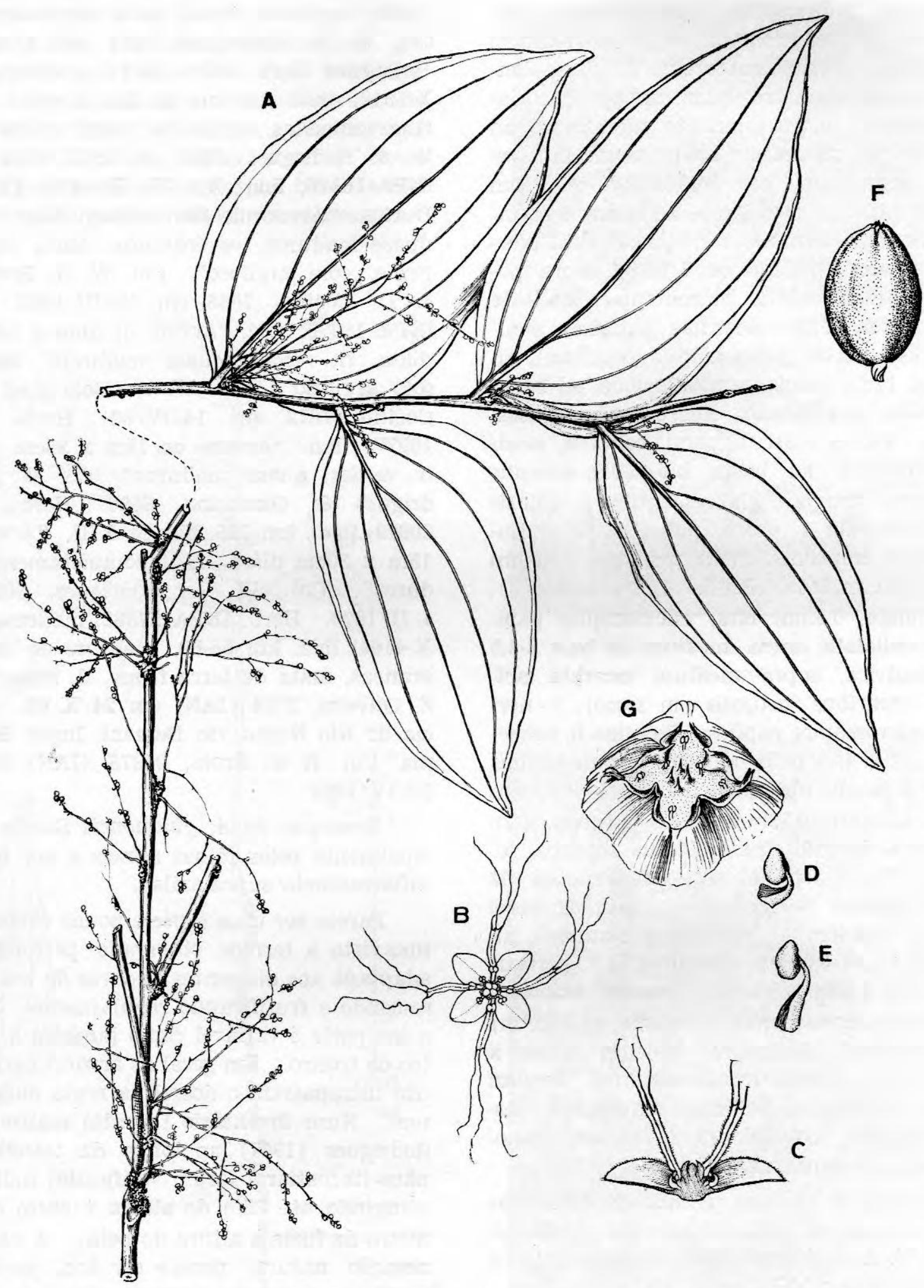

Fig. 1 - Anisophyllea manausensis Pires \& Rodr. n. sp. A., Hábito de ramo fértil. B., Flor masculina vista de cima. $C$., Flor masculina vista lateralmente. $D$. e E., Estames. $F$., Fruto. $G .$, Vista apical do fruto. (Desenho de Júlio Dellome Filho) 
subsessilia, pubescentia, mox glabrata, curvinervia, ovato-lanceolata, vulgo aliquantum asymetrica. Petioli subteretes ad $2 \mathrm{~mm}$ longi, $1,5-2 \mathrm{~mm}$ diametro. Lamina tenue coriacea, discolor, supra siccitate nigrescens, ad basin obtusa, ad apicem acuta, acuminata vel longe acuminata, ca. $9-17 \mathrm{~cm}$ x $4,5-7,5 \mathrm{~cm}$ (communiter $13 \times 6,5 \mathrm{~cm}$ ), ad marginem integra nonnunquam aliquantum revoluta. Nervi principales utrimque ca. 7 (6-8), supra modice impressi, subtus prominentes, siccitate nigrescentes. Inflorescentiae axillares pani. culis fasciculatis pauciramosis (spicatis), rigidis ad $12 \mathrm{~cm}$ longis, remotifloribus, ad basin incrassate granulosae, microscopice pubescentes. Flores masculi parvi, solitarii, sessiles, tetrameri, ad basin bracteolis singulis 0,5-1,0mm longis, glabrescentibus, ciliatis ornati. Sepala 4, ovata, pubescentia et microscopice imprimis, intus papilosa, $1,35 \mathrm{~mm}$ longa, $1,0 \mathrm{~mm}$ lata. Petala 4 (rarissime 5), $5 \mathrm{~mm}$ longa, $0,3 \mathrm{~mm}$ lata, microscopice papilosa et ciliolata, infra medium (e basi 2-2,5 $\mathrm{mm}$ ) indivisa, supra medium lacerata laciniis 3 linearibus tortuosis (in sicco), 1 -nervatis, microscopice papilosa. Stamina 8 , subaequalia, eis 4 sepalis oppositis vix majoribus ceteris 4 petalis oppositis, filamentis $0,7-1 \mathrm{~mm}$ longis, antheris $0,33 \mathrm{~mm}$ longis, 2-thecis, 4-1o cularibus, dorso-basifixis. Discus sinuatus 10 batus. Flores feminei non visi. Fructus vix maturi globosi vel globoso-elongati, drupacei (nuces), $3,5-4 \mathrm{~cm}$ longi $2,5-3 \mathrm{~cm}$ diametro, $\mathrm{ni}$ grescentes, 1-loculati (semper ?); pericarpium 2,5-3,5cm. crassum, parte exteriora (1-1,5mm) coriacea, ea interiora $(1,5-2 \mathrm{~mm})$ lignoso-ossea. Seminum unicum $(2 \mathrm{~cm} \mathrm{x}$ $1,5-2 \mathrm{~cm}$ ) ad apicem loculi adnatum demum in loculo liberum, pellicula tenuissima (testa) vestitum; cotyledones 2 crassae, planoconvexae, inaequaliae.

Habitat in Brasilia, Estado do Amazonas inter Manaus et Itacoatiara, ubi frequens. Typus W. A. Rodrigues 7211 (Holotypus INPA 16114, Isotypus MG).

Brasil, Estado do Amazonas, Estrada Manaus-Itacoatiara, $\mathrm{km} 135$, picada XV. "Árvore de $22 \mathrm{~m}$ alt. $\mathrm{x} 42 \mathrm{~cm}$ diâm., fl. masculina, mata de terra firme, solo areno-argiloso" Col. W. A. Rodrigues, 7211 em 4/X/1965. Holotypus Herb. INPA 16114, madeira INPA $\mathrm{X}-3318$; ibid. "Árvore de $22 \mathrm{~m}$ x $40 \mathrm{~cm}$ diâm, fl. esverdeadas, mata de terra firme". Col. W. A. Rodrigues, 7242 em 15/X/1965 Herb INPA 16176; ibid., km 27, Reserva Florestal Ducke. "Árvore de $10 \mathrm{~m}$ x $20 \mathrm{~cm}$ diâm., frutos quase maduros, esverdeados. Mata de terra firme, solo argiloso". Col. W. A. Rodrigues \& D. Coêlho, $7665 \mathrm{em} \mathrm{13/IV/1966.} \mathrm{Herb.}$ INPA 16970; ibid. "Árvore de $10 \mathrm{~m}$ x $18 \mathrm{~cm}$ de diâm., fr. verdes, quase maduros. Mata de solo argiloso". Col. W. A. Rodrigues \& D. Coêlho, 7672 em 14/IV/66. Herb. INPA 16977; ibid. "Árvore de $15 \mathrm{~m} \times 25 \mathrm{~cm}$ diâm., fr. verdes, quase maduros". Col. W. A. Rodrigues \& Osmarino, 8466. Herb. INPA 20979; ibid., km 125, picada XIII. "Árvore de $15 \mathrm{~m} \times 30 \mathrm{~cm}$ diâm., fr. incompletamente maduros". Col. W. A. Rodrigues, $8690 \mathrm{em}$ 4/II/1970. Herb. INPA 27862, madeira INPA $\mathrm{X}-4164$; ibid. $\mathrm{km}$ 55-60. "Árvore de $20 \mathrm{~m}$. fl. brancas, mata de terra firme, fl. masc.". Col. E. Oliveira, 2774 (IAN) em 24/X/63 . - Bacia do Rio Negro, rio Demeni, lugar Samaúma. Col. R. E. Froes, 28378 (IAN), fr. em $30 /$ IV $/ 1952$.

Separa-se de A. guianensis Sandw. principalmente pelas fôlhas sésseis e por não ter inflorescência supra-axilar.

Parece ser uma espécie pouco exigente de luz, visto a termos observado perfeitamente adaptada aos diferentes andares da mata, florescendo e frutificando regularmente. Não só o seu porte é variável como também o diâmetro do tronco. Em geral as árvores mais altas não ultrapassam o dossel da mata onde ocorrem. Num inventário florestal realizado por Rodrigues (1967) ao longo da estrada Manaus-Itacoatiara, foram verificados indivíduos atingindo até $25 \mathrm{~m}$ de altura e $66 \mathrm{~cm}$ de diâmetro de fuste à altura do peito. A sua regeneração natural parece ser boa, particularmente ao redor da árvore-matriz. As principais características da plântula (Fig. 2) vista na mata são as seguintes : raminhos subverticilares, levemente flexuosos, em vida esver- 
deados e depois de secos rufo-hirtelos; estípulas lanceoladas, subuladas, caducíssimas, glabras; eófilos um tanto coriáceos, ovado-lanceolados, ápice agudo-acuminado, subulado, base assimétrica, curtamente cuneada, margem inteira, bicolor, página superior verdeescura, glabra, pilosa apenas na base da nervura central; página inferior escamosa, ver-

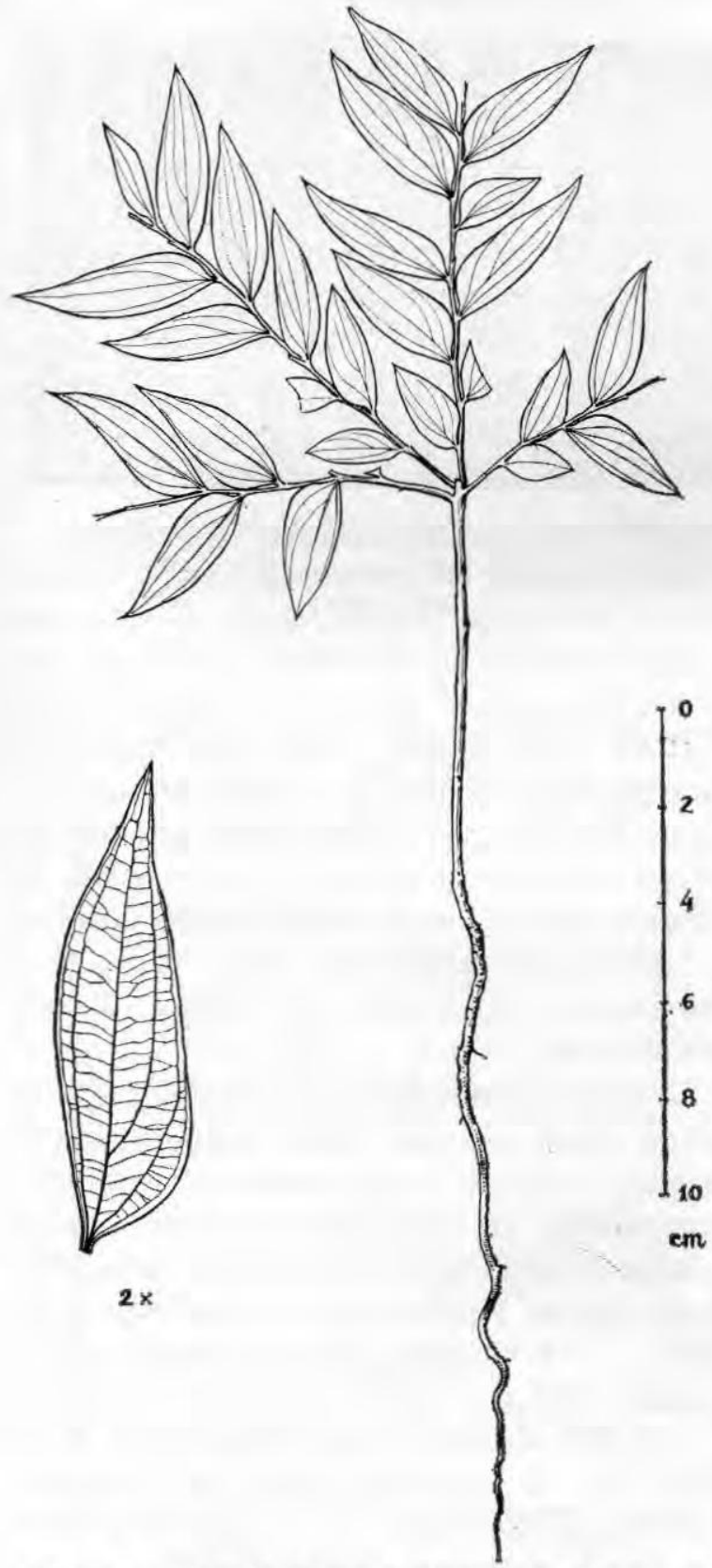

Fig. 2 - Desenho de uma plântula de Anisophyllea manausensis Pires \& Rodr., n. sp. (Desenho de Júlio Dellome Filho)

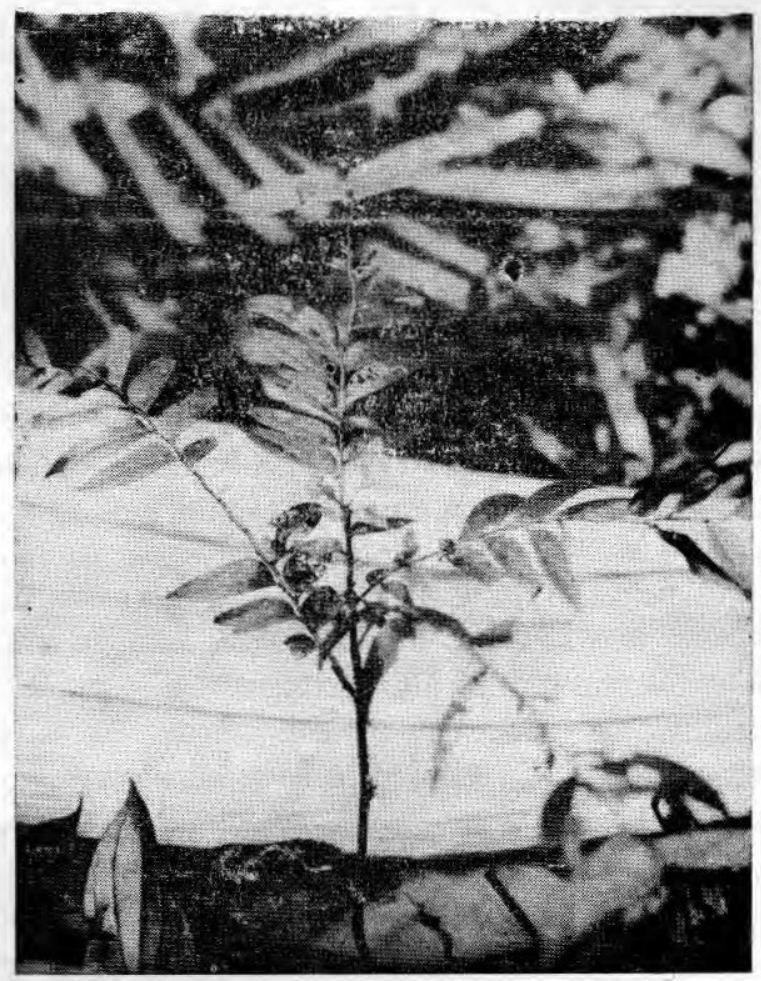

Fig. 3 - Plântula de Anisophyllea manausensis Pires \& Rodr.

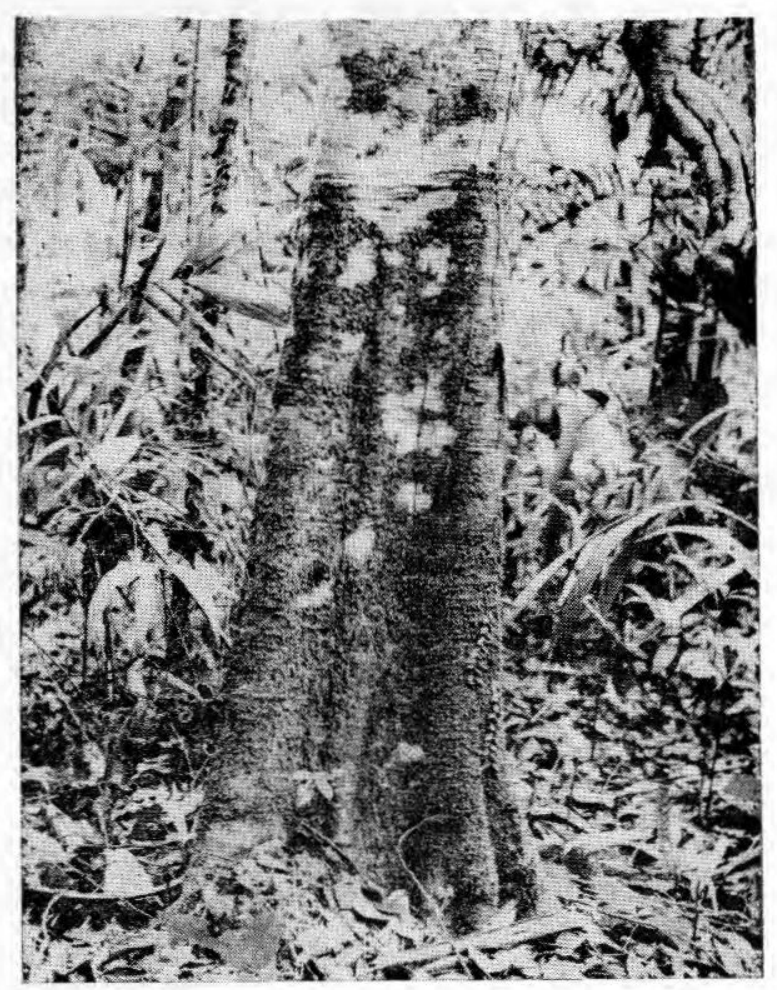

Fig. 4 - Tronco de Anisophyllea manausensis Pires \& Rodr. 
de-clara; curvinérveos com 4 nervuras principais.

Dentro da mata a nossa espécie é fàcilmente reconhecível pelas fôlhas velhas amareladas ou côr de palha caídas em seu redor. Raizes tabulares, quando ocorrem, são muito pequenas, aparecendo no entanto apenas ocasionalmente em árvores de maior diâmetro.

\section{MADEIRAS DE ANISOPHYLLEA}

E POLYGONANTHUS

Com base na anatomia da madeira Marco. (1935) e Metcalf \& Chalk (1965) dividem as Rhizophoraceae em três grupos. No Grupo II entram os gêneros Anisophyllea, Carallia, Combretocarpus, Crossostylis e Gynitroches.

A madeira de Polygonanthus não foi estudada por Marco. Na sua macroestrutura, vista com lente de 10 aumentos, (Fig. 5), parece-se muito com a de Anisophyllea (Fig. 6) e provàvelmente, deve pertencer ao Grupo II. Em ambos os gêneros, a estrutura macroscópica do lenho é bastante parecida com Euplassa e Panopsis das Proteaceae, devido especialmente aos raios largos, escassa distribuição dos poros, e ao farto parênquima concêntrico reticulado. O recente trabalho de Mennega (1966) sôbre os aludidos gêneros das Proteaceae serve de importante elemento de comparação sôbre o que nos estamos referindo. Calvino Mainieri, em informação pessoal, admite, no entanto, que a madeira de Polygonan-

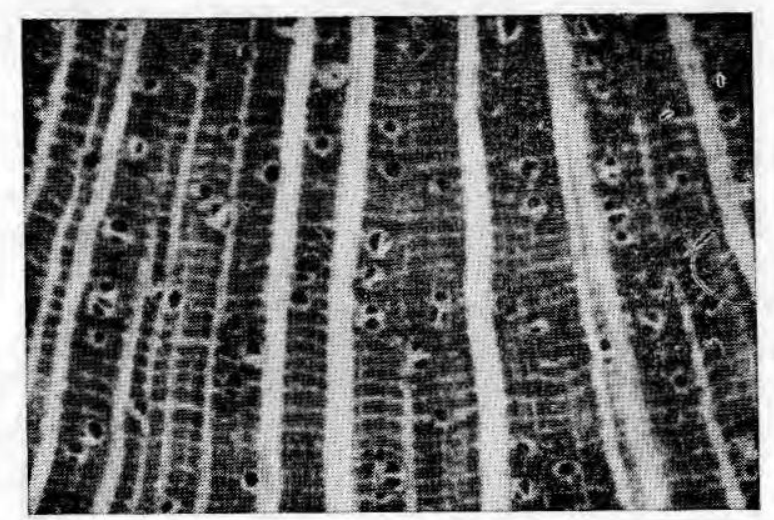

Fig. 5-Polygonanthus amazonicus Ducke. Secção transversal da madeira, 10X. (Pires, 53) thus, especialmente, é muitíssimo próxima de Euplassa, o mesmo não se dando com Anisophyllea.

A descrição das características gerais da madeira dos dois gêneros aqui abordados e seu aspecto macroscópico, seguem abaixo.

Anisophyllea manausensis Pires \& Rodrigues. (Fig. 6) .

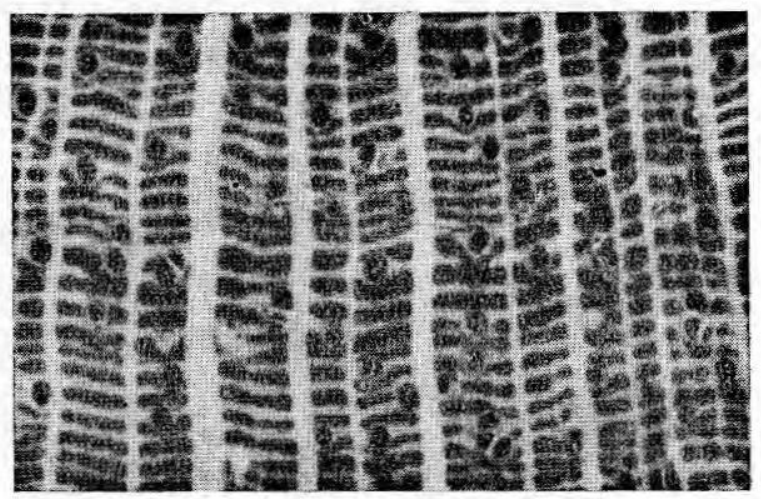

Fig. 6 - Anisophyllea manausensis Pires \& Rodr.. Secção transversal da madeira, 10X. (W. Rodrigues, 7211)

Características gerais - Madeira pesada $\left(0,85-0,90 \mathrm{~g} / \mathrm{cm}^{3}\right)$; cerne beje claro com manchas mais escuras, de aspecto fibroso atenuado; alburno não diferenciado; grã direita; textura média a grosseira; cheiro e gôsto indistintos; superfície de brilho pouco acentuado e levemente áspera ao tato; camada de crescimento demarcada por zonas fibrosas mais escuras.

Aspecto macroscópico - Parênquima visível a ôlho nu em linhas numerosas (3-4 por $\mathrm{mm}$ ), sinuosas, regularmente distribuidas, aproximadas, às vêzes interrompidas, ligando ou tangenciando os poros; na face radial visível em linhas longitudinais numerosas e pararelas; poros visíveis a ôlho nu, muito poucos a poucos (0-3 por $\left.\mathrm{mm}^{2}\right)$, pequenos a grandes (0 1-0,4 mm de diâm.), predominando os de 0,2-0,3 $\mathrm{mm}$ de diâmetro, solitários a maioria, às vêzes múltiplos de 2 ou 3 , alguns obstruidos; linhas vasculares visíveis a ôlho $\mathrm{nu}$ em linhas retas; raios no topo bastante contrastados, de três tipos distintos: largos e mé- 
dios visíveis a ôlho desarmado e regularmente distribuidos (1-2 por $\mathrm{mm}$ ) e os mais finos mais numerosos, apenas distintos sob lente; na face tangencial dispostos irregularmente, altos, visíveis a ôlho desarmado; na face radial reconhecíveis por manchas mais escuras Máculas medulares e canais secretores ausentes.

Material de referência - Xiloteca INPA X-2495 (W. Rodrigues s/n.); X-3145 (Lourenço $\mathrm{s} / \mathrm{n}$ ); X-3318 (W. Rodrigues 7211); X-4164 (W. Rodrigues 8690).

\section{Polygonanthus amazonicus Ducke (Fig. 5)}

Caracteristicas gerais - Madeira moderadamente pesada $\left(0,65 \mathrm{~g} / \mathrm{cm}^{3}\right)$; beje claro ou branco-amarelado, uniforme; cerne indistinto; grã direita; textura fina; superfície muito pouco lustrosa, um tanto áspera ao tato; gôsto e cheiro indistintos; camadas de crescimento levemente demarcadas por zonas fibrosas mais escuras.

Aspecto macroscópico - Parênquima apenas visível sob lente, em linhas muito finas, densas, aproximadas, levemente arqueadas, regulares, cortando ou tangenciando os poros; poros muito pequenos a pequenos, a maioria de $0,1 \mathrm{~mm}$ de diâmetro, muito poucos a pouco numerosos (3-5 por $\mathrm{mm}^{2}$ ), a maioria solitário, raramente múltiplos de 2 ou 3 , geralmente não obstruidos; raios de 3 tipos principais : os maiores, bem distintos a ôlho nu, os mais finos apenas visíveis sob lente, muito poucos a poucos (1-3 por $\mathrm{mm}$ ); no sentido longitudinal, visíveis a ôlho desarmado, na face tangencial, irregularmente dispostos, grossos e altos, e na face radial contrastados por faixas mais escuras.

Material de referência - Xiloteca INPA X-1969 (Pires, 53).

\section{CONCLUSÕES}

A posição sistemática do gênero amazônico Polygonanthus (com duas espécies) tem sido bastante discutida por diversos autores, que adotaram critérios muito discordantes. A opinião mais acertada sôbre o assunto foi apresentada por Kuhlmann em 1944, mostrando que o gênero se enquadrava perfeitamente na subfamília Anisophylleoideae das Rhizophoraceae.

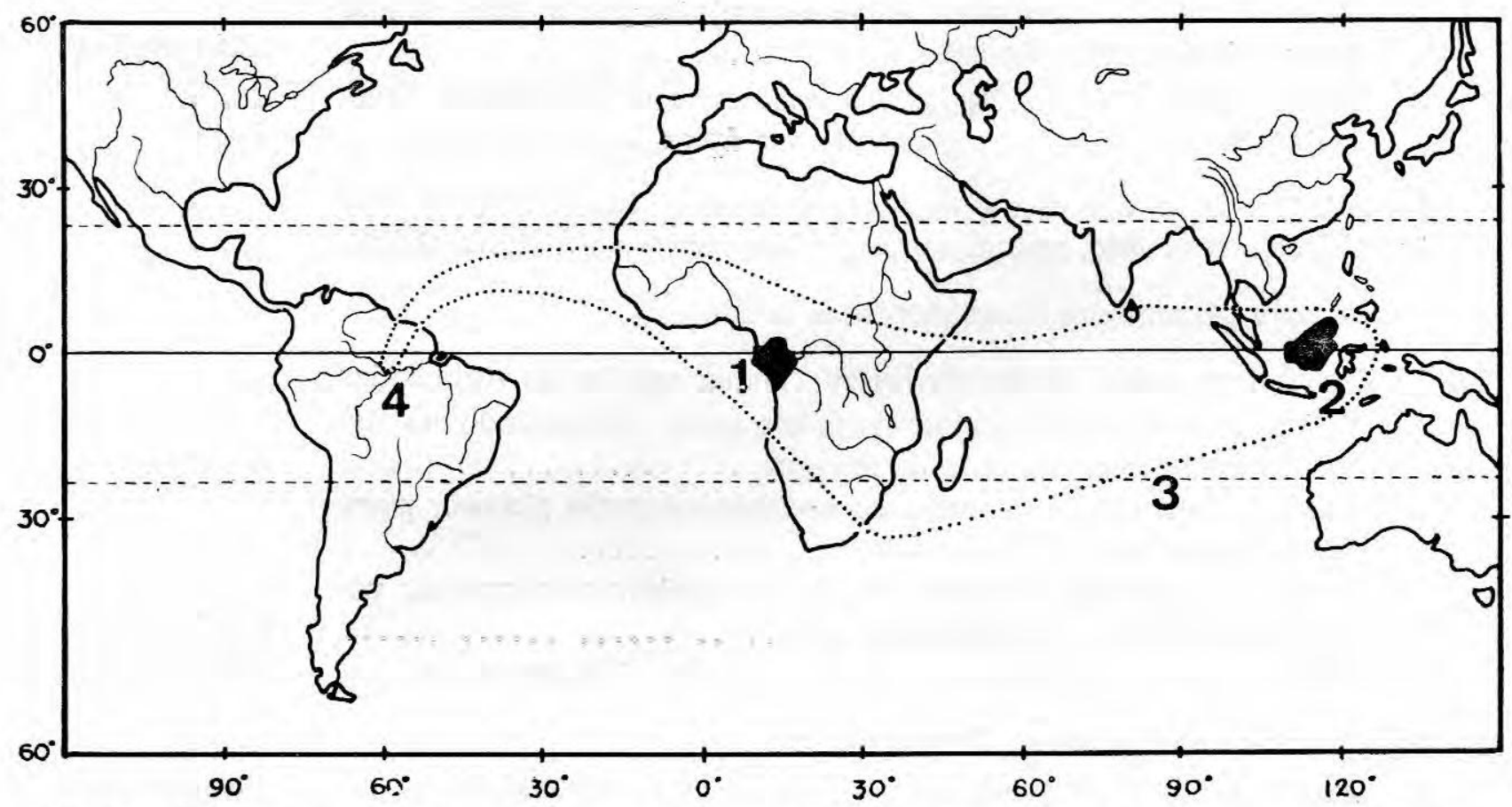

Fig. 7 - Área de dispersão das Anisophylleae: 1. Poga; 2. Combretocarpus; 3. Anisophyllea; 4. Polygonanthus e Anisophyllea neotropicais. 
A distribuição geográfica de Polygonanthus é muito curiosa. As duas espécies, $P$. amazonicus e $P$. punctulatus, são muito raras e vivem em áreas muito limitadas.

P. amazonicus foi encontrada pela primeira vez por Ducke em Maués, onde habita as praias do rio com areia branca.

Passados quase vinte anos, J. M. Pires a coletou novamente, ainda desta vez, na mesma localidade de Maués, única área até hoje conhecida da espécie.

$P$. punctulatus é da região do rio Negro, também nunca mais reencontrada, depois de descrita.

A descoberta de duas espécies de Anisophyllea na Amazônia, uma na Guiana e outra no Estado do Amazonas, constituiu-se numa interessante extensão da área de disper- são dêsse gênero que era considerado anteriormente como exclusivo do Velho Mundo. No mapa (Fig. 7) está representada a distribuição dos gêneros Anisophyllea, Combretocarpus, Poga e Polygonanthus.

Croizat, em 1943, criou a nova família Polygonanthaceae para abrigar o gênero Polygonanthus. Anteriormente, Ridley em 1922, Burkill em 1935 e Corner em 1940 já haviam tratado o gênero Anisophyllea dentro da família independente Anisophylleaceae.

O critério de se tratarem êsses quatro gêneros como família independente ou como uma secção da família Rhizophoraceae não tem grande importância. 0 importante é ficar definitivamente esclarecido as suas relações de afinidade. A sua separação pode ser feita de acôrdo com a chave abaixo.

Chave para gêneros da Secção Anisophylleae

1. Fruto Alado

2. Bornéu. Pétalas franjadas

Combretocarpus

2. Amazônia brasileira. Pétalas inteiras Polygonanthus

1. Fruto não alado, globoso

3. Velho Mundo e Amazônia. Pétalas franjadas muito mais longas que as sépalas, sem glândulas $\ldots \ldots \ldots \ldots \ldots \ldots \ldots \ldots$

3. Africa (Gabão). Petalas pouco maiores que as sépalas, trilobadas ou franjadas, com glândulas no ápice ..............

Anisophyllea

Poga

De acôrdo com o que ficou exposto, os gêneros das Rhizophoraceae brasileiras, sensu lato, podem ser separados conforme a chave abaixo.

Chave para gêneros das Rhizophoraceae brasileiras

1. Estilête único; ovário súpero ou ínfero Fôlhas opostas ou verticiladas

2. Ovário ínfero; fôlhas opostas; fruto comprido germinando na árvore; raizes escoras; planta de mangue $\ldots \ldots \ldots \ldots \ldots \ldots . . . . . .$.

2. Ovário súpero; fôlhas opostas ou verticiladas; fruto globoso; plan-

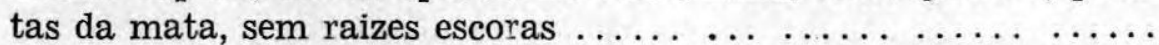

3. Fôlhas opostas; não obovadas. Arbustos ou árvores pequenas; pé-

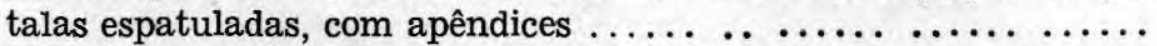

3. Fôlhas verticiladas, obovadas. Árvore grande. Pétalas laciniadas

Rhizophora

Cassipourea

Sterigmapetalum

1. Estilêtes 3-4; ovário ínfero. Fôlhas alternas.

4. Fruto obcônico, coriáceo, com 4 asas; pétalas não laciniadas ...

4. Fruto globoso, com endocarpo ósseo, sem asas; pétalas com a

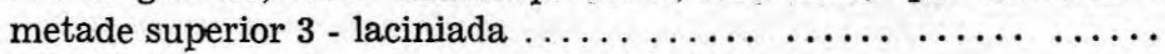

Polygonanthus

Anisophyllea 


\section{SUMMARY}

This paper is a contribution to elucidate an obscure problem which involves relationship of a group of plants containing the genera Anisophyllea, Polygonanthus, Combretocarpus and Poga. Genus Anisophyllea is native in both the Old and New Worlds; Polygonanthus is exclusively Amazonian; and Combretocarpus and Poga are confined to the Old World. It is a very interesting subject relating to the problems of evolution, speciation and distri. bution of plants, and supports the theories which endeavour to explain the centuries-old story that South America and Africa were, at one time, connected geographically.

Taxonomic position of genera Anisophyllea and Polygonanthus is discussed.

A new species of genus Anisophyllea is described. General characteristics and macroscopic descriptions of the woods of Polygonanthus amazonicus and Anisophyllea manausensis are presented.

Keys for identification of the genera of Section Anisophyllea and of Brazilian Rhizophoraceae are shown.

\section{BIBLIOGRAFIA CITADA}

Baehni, C. \& Dansereau, P.

1939 - Polygonanthus, genre de Saxifragaceae. Bull. Soc. Bot. France, $86: 183-186$.

BAILLON, H. E.

1877 - Histoire des Plantes. $6: 292-294$.

CORNER, E. J. H.

1952 - Wayside trees of Malaya. 2. ed. 1:122-125.

Croizat, L. M. C.

1939a-- Polygonantheae (Olacaceae). Bull. Soc. Bot. France, $86: 5-7$.

1939b- Polygonanthus, not a genus of the Saxifragaceae. Jour. Arnold Arbor., 20(4) : 443-445.

1943 - Polygonanthaceae. Cactus Succ. Jour., Los Angeles, 15(5): 64 .
DUCKe, A .

1932 - Folygonanthus. Notizbl. Bot. Gart. Mus. Berl. $11: 345-346$.

1933 - Folygonanthus. Arch. Jard. Bot., Rio de Ja neiro, $6: 62-63$.

ERdTMANN, G.

1966 - Pollen morphology and plant taxonomy. An. giosperms. New York \& London, Hafner publ. Co. $1: 401$.

Kuhlmann, J. C.

1940 - Folygonanthus punctulatus. In: Reun. Su!Amer. Bot., 1a., 1938. 3:80-82.

1944 - Nota prévia. Rodriguésia, 8(17): 65.

MARCO, H. F.

1935 - Systematic anatomy of the woods of the Rhizophoraceae. Frop. Woods, $44: 1-20$.

MENNEGA, A. W

1966 - V/ood anatomy of the genus Euplassa and its relation to other Proteaceae of the Guianas and Brasil. Acta Bot. Neerl., 15 : 117-129.

Metcalfe, C. R. \& Chalk, L.

1965 - A natomy of the Dicotyledons. Oxford, Clarendon Press. 1: 601-612.

RIDLEY, H. N.

1922 - Flora of the Malay Peninsula. London, L. Reeve \& Co. Ltda., 1:700

ROBERTY, G.

1954 - Petite Flore de l'Ouest Africain. Paris, Rech. Szi. Techn. Outre-Mer.

Rodrigues, W. A.

1967 - Inventário florestal pilôto ao longo da estrada Manaus-Itacoatiara, Estado do Amazonas: dados preliminares. Atas Simp. sôbre Biota Amazônica, 7 (Conservaçäo da natureza e recursos naturais) : 257-267.

SANDWITH, N. Y.

1952 - Contribuition to the flora of Tropical America: LV - Discovery of Anisophyllea in America Kew Bull., : 303-306. 